\title{
A fuzzy sliding mode for Planar 4-Cable Direct Driven Robot
}

\section{(Controlador por modos deslizantes difuso para un robot planar accionado por cuatro cables)}

\author{
Xavier Aguas ${ }^{1}$, Andres Cuaycal ${ }^{1}$, Israel Paredes ${ }^{1}$, Marco Herrera ${ }^{1}$
}

\begin{abstract}
:
Cable Direct Driven Robots (CDDRs) are a special class of parallel robots but they are formed by replacing all the supporting rigid links with cables. Compare with traditional robots, these robots are good candidates for performing a wide range of potential applications. A Planar CDDR model is considered in this paper since no rotational move and no moment resistance are required on the end-effector, all 4 cables convene in a single point and the end-effector is modeled as a point mass. The main goal of this paper is to present a new approach in control by developing a Sliding Mode Controller (SMC) with a Fuzzy-PI as sliding surface using Fuzzy logic toolbox in Matlab/Simulink. The tests performed were Step change reference test and Tracking trajectory test to observe the behavior of the cables during the trajectory and the end-effector movement. Simulation was carried out on Planar 4-Cable CDDR to prove the effectiveness of the proposed control law and the results were compared with a PI Controller and a conventional SMC in terms of integral square error (ISE) index. Only the kinematic model of Planar 4-Cable CDDR is considered in this paper.
\end{abstract}

Keywords: cable direct driven robot; sliding mode control; Fuzzy controller; PI controller; kinematic.

\section{Resumen:}

Los Robots accionados por cable (CDDR) son una clase especial de robots paralelos, pero se forman al reemplazar todos los enlaces rígidos de soporte por cables. En comparación con los robots tradicionales, estos robots son buenos candidatos para realizar una amplia gama de aplicaciones potenciales. En este documento se considera el modelo de un robot planar accionado por cables porque no se requieren movimientos de rotación, momentos de resistencia y los cables se reúnen en un solo punto conocido como efector final el cual se modela como una masa puntual. El objetivo principal de este documento es presentar un nuevo enfoque en el control mediante el desarrollo de un controlador por modos deslizantes (SMC) con una superficie deslizante difusa tipo PI utilizando Fuzzy logic toolbox en Matlab / Simulink. Las pruebas realizadas fueron: prueba de cambio de referencia y prueba de seguimiento de trayectoria para observar el comportamiento de los cables durante la trayectoria y el movimiento del efector final. La simulación se llevó a cabo en un robot planar accionado por cuatro cables para probar la efectividad de la ley de control propuesta y los resultados se compararon con un controlador PI y un SMC convencional en términos del índice de la integral del error cuadrático (ISE). Solo el modelo cinemático del CDDR de 4 cables planar se considera en este documento.

Palabras clave: robot accionado por cables; control por modos deslizantes; controlador difuso; controlador PI; cinemática.

\footnotetext{
${ }^{1}$ Escuela Politécnica Nacional, Quito, Ecuador ( \{xavier.aguas, andres.cuaycal, israel.paredes, marco.herrera\} @epn.edu.ec).
} 


\section{Introduction}

Robots have made formidable progress into industries for manufacturing and assembly. Traditional robots with serial or parallel structures are unsuitable since the workspace requirements are higher as in (Oh \& Agrawal, 2003) are presented. For these motives, cable-driven mechanisms have received attention and have been recently studied. The advantages shown in (Zanotto, 2011), cables and tendon-like components in robotics have catched the interest of many researchers in the last years. Cable-direct-driven robots (CDDRs) are structurally similar to parallel robots (Jin et al., 2013) (Williams, Gallina, \& Rossi, 2001) wherein the end-effector is supported in parallel by $n$ cables with $n$ tensioning motors. As compared to rigid links, cables are lighter and can handle larger loads guaranteeing considerable ranges of motion. However, one disadvantage is cables can only exert tension and cannot push on the end-effector. This property makes feedback control of CDDRs more defiant than conventional parallel robot as in (Babaghasabha, Khosravi, \& Taghirad, 2014) is designed an adaptive controller in task space coordinates for a planar cable-driven parallel robot with uncertainties in dynamic and kinematic parameter or as in (Khosravi \& Taghirad, 2014) a robust PID controller is presented for the cable-driven robot to ensure that all cables remain in tension. On the other hand, sliding mode control (SMC) is a nonlinear technique with robustness against the model uncertainties and ability of the disturbance rejection as in (Ataei \& Shafiei, 2008) which introduced a SMC for a robot manipulator in order to deleting the oscillations of the response. Fuzzy control affords a methodology for representing, manipulating, and implementing a human's heuristic knowledge about how to control a system. Fuzzy logic presents the ability to imitate the human mind to effectively occupy modes of reasoning that are approximate rather than exact. Designing of a Fuzzy Logic Controller (FLC) can show a lengthy process when performed heuristically (Nabi, 2013). FLC is identical to a conventional PID controller (Ghosh, Sen, \& Dey, 2015). In case of FLC, control strategies are expressed in terms of fuzzy rules and this set of well-defined rules is known as fuzzy algorithm. Planar 4-Cable CDDR mode (Gallina, Rossi, \& Williams II, 2001) is considered in this paper since no rotational move and no moment resistance are required on the endeffector, all 4 cables convene in a single point and the end-effector is modelled as a point mass. A Sliding Mode Control with a Fuzzy PI as sliding surface for the kinematic model of Planar 4-Cable CDDR is proposed. The performance of this controller is compared with a $\mathrm{PI}$ Controller and a conventional SMC in terms of integral square error (ISE) index. The simulation results show the ability the proposed controller in comparison with the conventional controllers for trajectory tracking and step change reference.

\section{Methodology}

\subsection{Model of Planar 4-Cable Direct Driven Robot}

In this paper, we use only the reverse kinematic pose solution (Williams li \& Gallina, 2003). Given the position $P_{r}=\left[\begin{array}{ll}x & y\end{array}\right]^{T}$ is found the cable lengths $L_{i}(i=1, \ldots, 4)$. The endeffector position $P_{r}=\left[\begin{array}{ll}x & y\end{array}\right]^{T}$ is possible to get by geometrical considerations (Euclidean Norm) with each fixed ground link vertex $A_{i}$ (Motor Position). In Figure 1 shows the Planar 4-Cable CDDR scheme. It is important to mention which each cable angle depend of quadrant.

The reverse kinematics pose solution is given in Equation 1,

$$
L_{i}=\sqrt{\left(x-A_{i x}\right)^{2}+\left(y-A_{i y}\right)^{2}}
$$


and the cable angles are given by Equation 2 .

$$
\tan ^{-1}\left(\frac{y-A_{i y}}{x-A_{i x}}\right)
$$

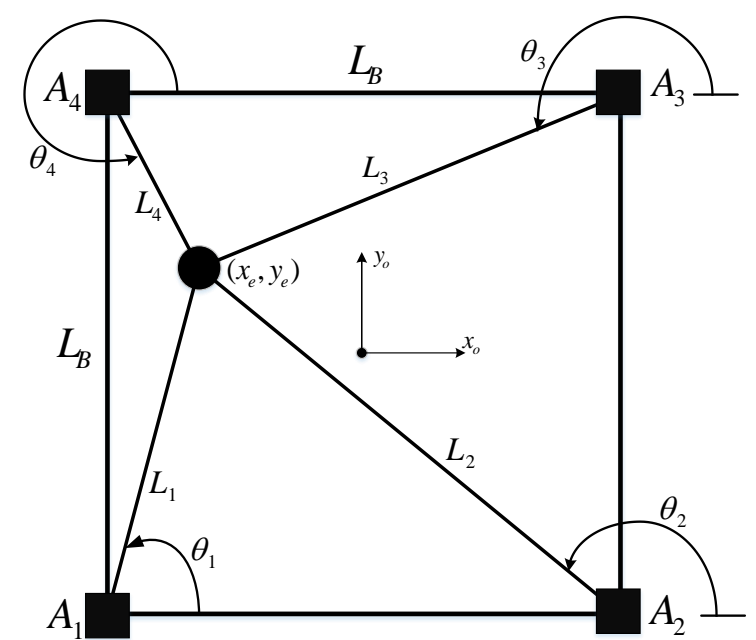

Figure 1. Planar 4-Cable CDDR Scheme.

Considering the $i^{\text {th }}(i=1, \ldots, 4)$ cable vector-loop closure equation $\left[\begin{array}{ll}x & y\end{array}\right]^{T}=\left[A_{i x}+\right.$ $\left.L_{i} \cos \theta_{i} \quad A_{i y}+L_{i} \sin \theta_{i}\right]^{T}$ is calculated in the velocity kinematics Equations 3 and 4.

$$
\left[\begin{array}{c}
\dot{x} \\
\dot{y}
\end{array}\right]=\left[\begin{array}{cc}
\cos \theta_{i} & -L_{i} \sin \theta_{i} \\
\sin \theta_{i} & L_{i} \cos \theta_{i}
\end{array}\right]\left[\begin{array}{c}
L_{i} \\
\dot{\theta_{l}}
\end{array}\right]
$$

Inverting $i^{\text {th }}$ cable Jacobian matrix we have Equation 4.

$$
\left[\begin{array}{c}
\dot{L}_{l} \\
\dot{\theta}_{l}
\end{array}\right]=\left[\begin{array}{cc}
\cos \theta_{i} & \sin \theta_{i} \\
\sin \theta_{i} / L_{i} & -\cos \theta_{i} / L_{i}
\end{array}\right]\left[\begin{array}{c}
\dot{x} \\
\dot{y}
\end{array}\right]
$$

In order to build the inverse velocity solution of Planar 4-Cable CDDR $\left(\dot{L}=J \dot{P}_{r}\right)$ is necessary to eliminate the second row $\dot{\theta}_{l}$ as (Williams li \& Gallina, 2003) to relation the cable length rates and the end-effector velocity as shown in Equation 5.

$$
\left[\begin{array}{l}
\dot{L_{1}} \\
\dot{L_{2}} \\
\dot{L_{3}} \\
\dot{L_{4}}
\end{array}\right]=\left[\begin{array}{ll}
\cos \theta_{1} & \sin \theta_{1} \\
\cos \theta_{2} & \sin \theta_{2} \\
\cos \theta_{3} & \sin \theta_{3} \\
\cos \theta_{4} & \sin \theta_{4}
\end{array}\right]
$$

The alternate forward velocity solution with $\dot{L}$ as inputs, is calculated through the left pseudoinverse Equation 6,

$$
\dot{P}_{r}=J^{*} \dot{L}
$$

where $J^{*}=\left(J^{T} J\right)^{-1} J^{T}$ is the left pseudoinverse. 


\subsection{Design of controllers for Planar 4-Cable Cable Direct Driven Robot}

This section designs different controllers for Planar 4-Cable (CDDR) based on the kinematic model. The designed controllers are a PI Controller, a conventional SMC and a Fuzzy Logic Controller.

\subsubsection{PI Controller}

In order to design a PI controller, it is necessary to know the error. The control scheme of this controller is presented in Figure 2.

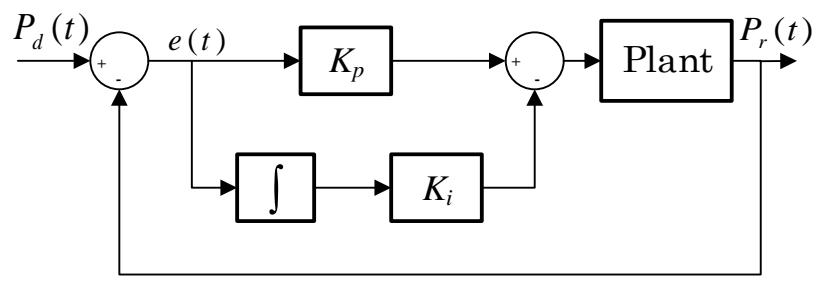

Figure 2. PI control scheme.

The tracking error vector is defined in Equation 7,

$$
e(t)=P_{d}(t)-P_{r}(t)
$$

where $P_{d}(t)$ is the desired position vector and $P_{r}(t)$ is the robot position vector.

This controller has the form given in Equation 8.

$$
P I(t)=K_{p} e(t)+K_{i} \int_{0}^{t} e(t) d t
$$

Applying this controller to the kinematic model of Planar 4-Cable CDDR is necessary to multiply by $J$, getting $\dot{L}_{i}$ as control actions, as in Equation 9,

$$
C(t)=\dot{L}_{i}=J\left(K_{p} e(t)+K_{i} \int_{0}^{t} e(t) d t\right)
$$

where $K_{p}$ and $K_{i}$ are tuning parameters. These parameters have been selected by trial and error until achieving the lowest ISE index.

\subsubsection{Sliding Mode Controller}

This section shows the design of a SMC with a PI sliding surface (See Figure 3) from the kinematic model of Planar 4-Cable CDDR as in (Villacres, Herrera, Sotomayor, \& Camacho, 2017) designs a conventional SMC with a PID sliding surface.

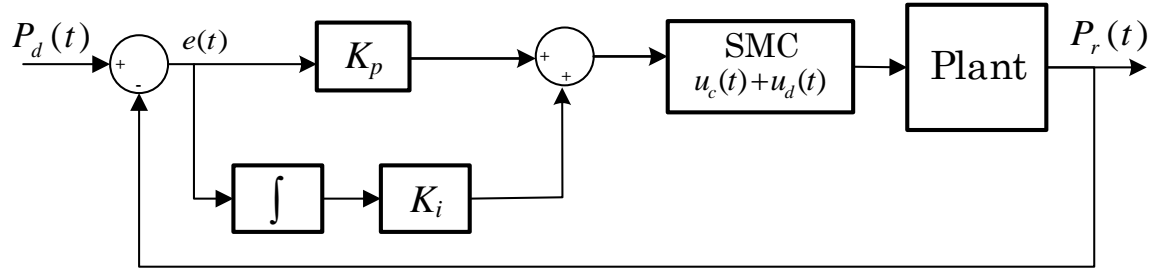

Figure 3. SMC control scheme. 
In order to design a conventional SMC, this sliding surface is considered as in Equation 10,

$$
\sigma(t)=\left(\frac{d}{d t}+\lambda\right)^{n} \int e(t) d t
$$

where $n$ is the order of the system and $\lambda$ is a positive constant.

This controller has two components: a continuous $u_{c}(t)$ and a discontinuous $u_{d}(t)$, shown in Equation 11.

$$
u(t)=u_{c}(t)+u_{d}(t)
$$

The system studied is the first order $n=1$ for this reason the derivative part of the surface is eliminated. The surface is expressed as in Equation 12.

$$
\sigma(t)=e(t)+\lambda \int e(t) d t
$$

Now, the surface must be derived for the development of the controller (Equation 13).

$$
\dot{\sigma}(t)=\dot{e}(t)+\lambda e(t)
$$

By substituting Equation 7 in Equation 13 we have Equation 14.

$$
\dot{\sigma}(t)=\left(\dot{P}_{d}(t)-\dot{P}_{r}(t)\right)+\lambda e(t)
$$

By replacing Equation 6 in Equation 14, $\dot{\sigma}(t)$ it can be rewritten as in Equation 15.

$$
\dot{\sigma}(t)=\left(\dot{P}_{d}(t)-J^{*} \dot{L}\right)+\lambda e(t)
$$

The continuous part of the controller is provided with the condition to keep the output on the sliding surface $\dot{\sigma}(t)=0$ and considering the control law as $u_{c}(t)=\dot{L}$ (Equation 16).

$$
u_{c}(t)=J\left(\dot{P}_{d}(t)+\lambda e(t)\right)
$$
Equation 17,

By completing the SMC control law, the discontinuous part $u_{d}(t)$ is added in

$$
u_{S M C}=J\left[\dot{P}_{d}(t)+\lambda e(t)\right]+J\left[k_{1} \operatorname{sign}(\sigma(t))\right]
$$

where $u_{d}(t)$ is responsible for reaching sliding surface and is composed of a nonlinear function $\operatorname{sign}(\sigma(t))$ which switches about the sliding surface and $k_{1}>0$ is a tuning parameter. These considerations were taken from (Herrera, 2017).

In order to design $u_{d}(t)$ a positive-definite Lyapunov function $V$ is defined in Equation 18.

$$
V=\frac{1}{2} \sigma(t)^{T} \sigma(t)>0
$$


The derivative of the function $V$ must be negative-definite (Equation 19).

$$
\dot{V}=\sigma(t)^{T} \dot{\sigma}(t)<0
$$

By replacing equation 15, $\dot{V}$ is as in Equation 20.

$$
\dot{V}=\sigma(t)^{T}\left[\left(\dot{P}_{d}(t)-J^{*} \dot{L}\right)+\lambda e(t)\right]
$$

The control law is defined as $\dot{L}=u_{c}(t)+u_{d}(t)$ and substituting we have Equation 21 .

$$
\dot{V}=\sigma(t)^{T}\left[\left(\dot{P}_{d}(t)-J^{*}\left(u_{c}(t)+u_{d}(t)\right)\right)+\lambda e(t)\right]
$$

To satisfy Equation 19 and replacing Equation 16 in Equation 21, $\dot{V}$ should be as in Equation 22,

$$
\dot{V}=\sigma(t)^{T}\left[-J k_{1} \operatorname{sign}(\sigma(t))\right]<0
$$

where $k_{1}>0$.

Therefore, by analyzing (Equation 23):

$$
\begin{array}{llll}
\text { if } & \sigma(t)>0 & \rightarrow & \operatorname{sign}(\sigma(t))>0 \\
\text { if } & \sigma(t)<0 & \rightarrow & \operatorname{sign}(\sigma(t))<0
\end{array}
$$

Finally, to reduce the chattering effect (Camacho \& Smith, 2000), $u_{d}(t)$ can be rewritten as a sigmoid function in Equation 24,

$$
u_{d}(t)=J\left[k_{1} \frac{\sigma(t)}{|\sigma(t)|+\delta}\right]
$$

where $\delta$ is a chattering parameter reduction.

\subsubsection{Fuzzy - Sliding Mode Controller}

In this section, PI-Fuzzy sliding surface is proposed to a conventional SMC. The selection of this surface is based on the qualitative knowledge about the process to be controlled and was designed using Fuzzy logic toolbox in Matlab/Simulink. For the surface design, there are two inputs and one output. The surface is defined by Equation 25.

$$
\sigma(t)=s_{F}\left(e(t), \int_{0}^{t} e(t) d t\right)
$$

The control scheme of Fuzzy-SMC Controller is shown in Figure 4.

The Member Functions (MFs) are namely, NB (Negative Big), NM (Negative Medium), NS (Negative Small), ZE (Zero), PS (Positive Small), PM (Positive Medium), and PB (Positive Big) which are defined as symmetric triangles having $50 \%$ overlap. These MFs are shown in Figure 5. For the two input variables (error and integral error), the range for universe of discourse is [-2 2] and for the output variable (action control), it is defined in the range [-0.6 0.6] (Ghosh et al., 2015). 


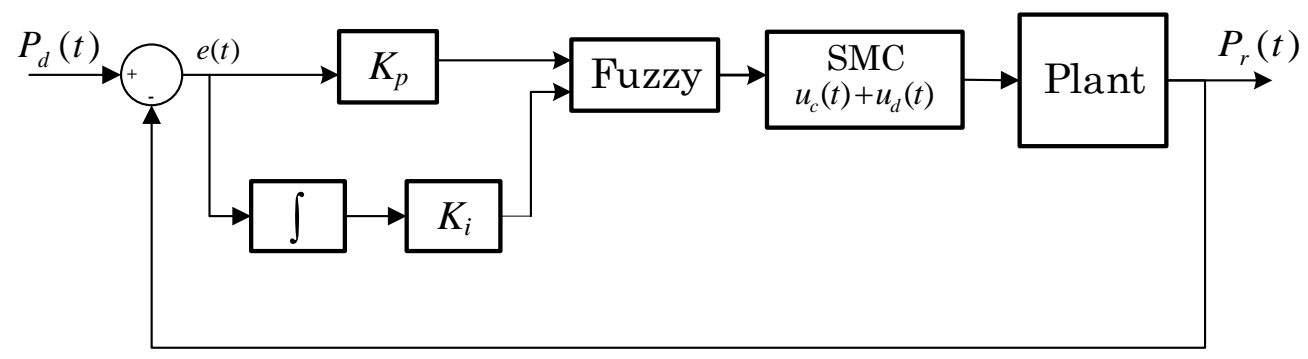

Figure 4. Fuzzy-SMC control scheme
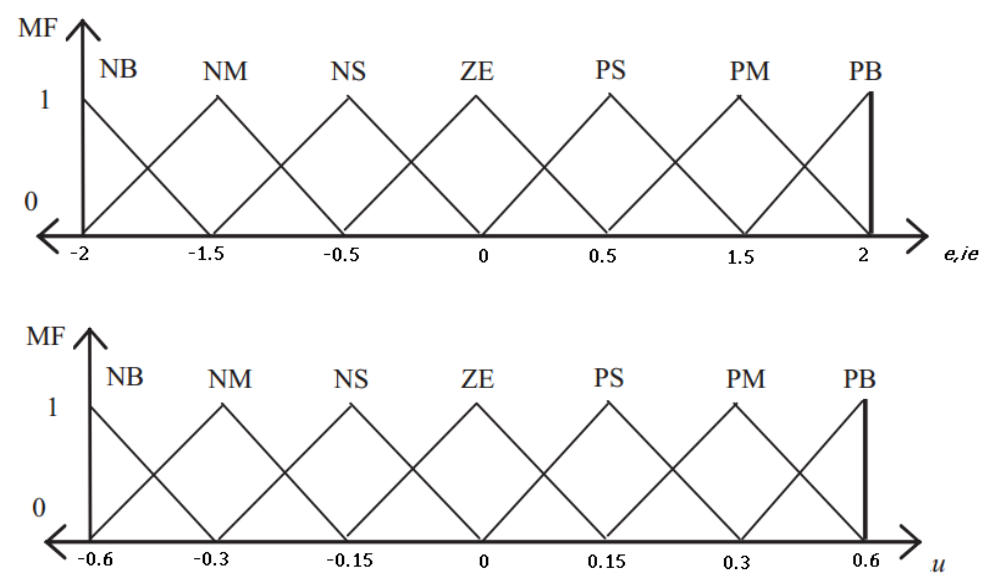

Figure 5. MFs for the input and output variables.

The selected rules for the sliding surface are listed in Table 1. The forty-nine fuzzy rules are based on sliding mode principle (Palm, 1992).

Table 1. Fuzzy Control Rules.

\begin{tabular}{|c|c|c|c|c|c|c|c|}
\hline $\int \boldsymbol{e} / \boldsymbol{e}$ & NB & NM & NS & ZE & PS & PM & PB \\
\hline NB & NB & NB & NB & NM & NS & NS & ZE \\
\hline NM & NB & NB & NM & NM & NS & ZE & PS \\
\hline NS & NB & NM & NM & NS & ZE & PS & PM \\
\hline ZE & NB & NM & NS & ZE & PS & PM & PB \\
\hline PS & NM & NS & ZE & PS & PM & PM & PB \\
\hline PM & NS & ZE & PS & PM & PM & PB & PB \\
\hline PB & ZE & PS & PM & PM & PB & PB & PB \\
\hline
\end{tabular}

\section{Simulation results}

The controllers were implemented in Matlab/Simulink 2017a using the kinematic model of Planar 4-Cable CDDR. The tests were run on a computer with an Intel(R)Core(TM) i7-5500U CPU @ 2.40GHz with 8,00 GB RAM, running Windows 10. Figure 6 shows the simulator developed to observe the behavior of the cables during the trajectory. Two tests were performed:

- Step Change Reference Test

- Tracking Trajectory Test

The simulation had a duration of 110 seconds with a sampling time of 0.1 for each test and uses ODE45 (Solve non-stiff differential equations). The physical parameters of Planar 4-Cable CDDR are presented in Table 2. 
Table 2. Parameters Planar 4-Cable CDDR.

\begin{tabular}{|c|c|c|}
\hline Parameter & Unit & Description \\
\hline$A_{1}=(-0.35,-0.35)$ & {$[\mathrm{m}]$} & Motor position 1 \\
\hline$A_{2}=(0.35,-0.35)$ & {$[\mathrm{m}]$} & Motor position 2 \\
\hline$A_{3}=(0.35,0.35)$ & {$[\mathrm{m}]$} & Motor position 3 \\
\hline$A_{4}=(-0.35,0.35)$ & {$[\mathrm{m}]$} & Motor position 4 \\
\hline
\end{tabular}

Finally, the values of $K_{p}$ and $K_{i}$ for PI Controller and $\lambda, k_{1}$ and $\delta$ for SMC have been selected by trial and error until achieving the lowest ISE index. In Table 3 are shown these values.

Table 3. Tuning parameter for the controllers

\begin{tabular}{|c|c|}
\hline Tuning Parameter & Value \\
\hline$K_{p}$ & 10 \\
\hline$K_{i}$ & 0.08 \\
\hline$\lambda$ & 0.5 \\
\hline$k_{1}$ & 1 \\
\hline$\delta$ & 0.1 \\
\hline
\end{tabular}

We used Equations 26 and 27 to compare the controllers based on ISE index. $\Delta_{1}$ corresponds to the comparison between conventional SMC and Fuzzy-SMC Controller and $\Delta_{2}$ corresponds to the comparison between PI Controller and the control law proposed,

$$
\begin{aligned}
& \Delta_{1} \%=\frac{e_{1}-e_{2}}{\frac{e_{1}+e_{2}}{2}} \cdot 100 \\
& \Delta_{2} \%=\frac{e_{1}-e_{3}}{\frac{e_{1}+e_{3}}{2}} \cdot 100
\end{aligned}
$$

where $e_{1}, e_{2}$ and $e_{3}$ represent error values for Fuzzy-SMC Controller, PI Controller and conventional SMC respectively.

\subsection{Step change reference test}

In this test, a step change reference is made from the reference $X_{r}=\left[\begin{array}{ll}0 & 0\end{array}\right]$ to the point $X_{d}=[0.2-0.2]$. In Figure 6 illustrates the end-effector path.

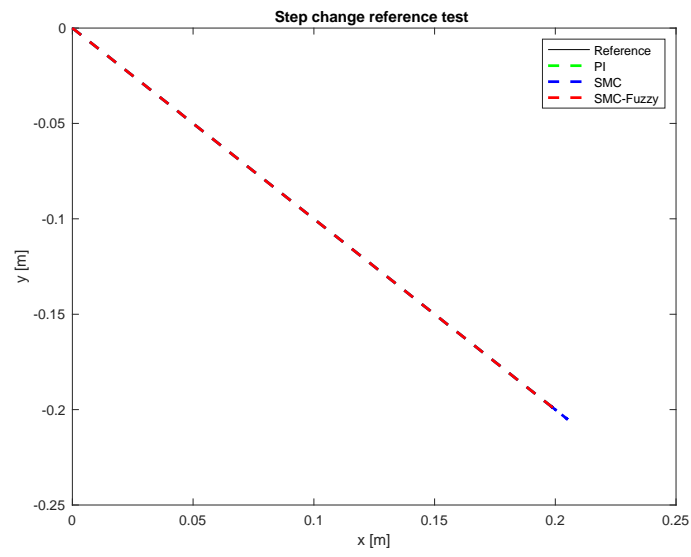

Figure 6. XY Graph, step change reference. 
Figure 7 presents $x$ and $y$ end-effector positions during the change reference to the position $X_{d}=[0.2-0.2]$. The percentage overshoot of Fuzzy-SMC Controller is less than conventional SMC and the setting time is lower than PI Controller.
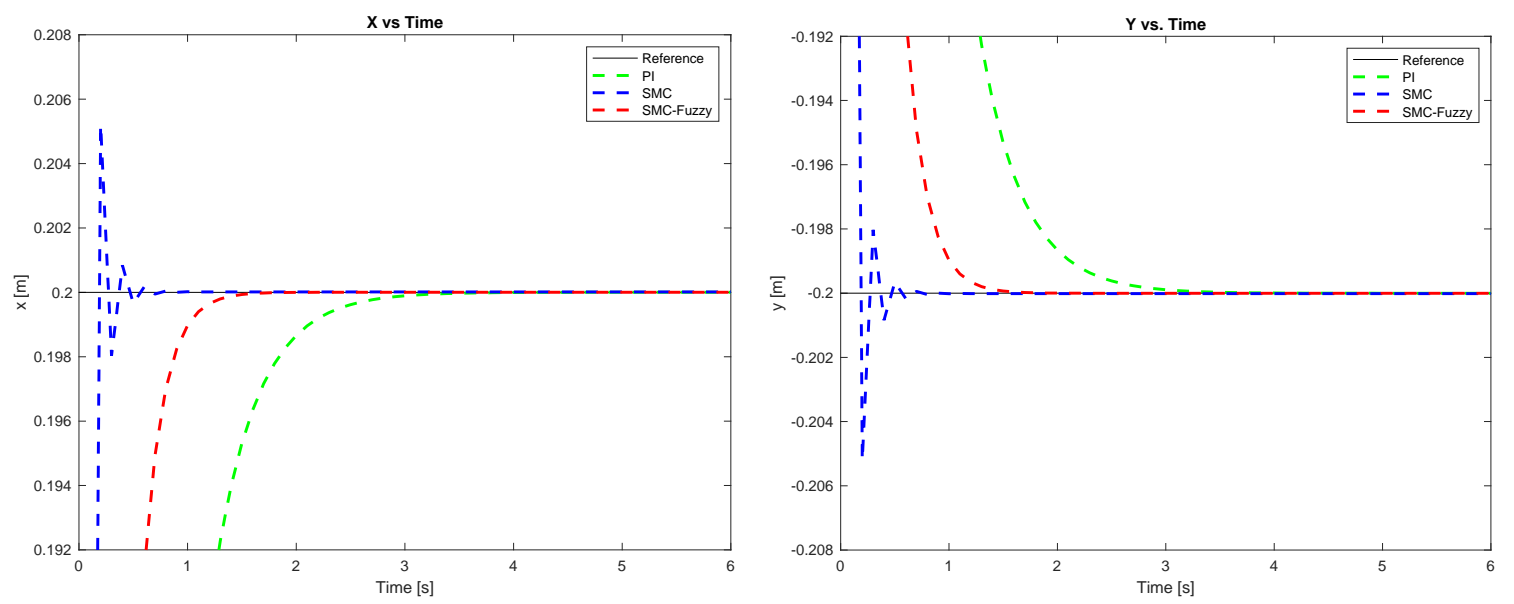

Figure 7. $x$ and $y$ end-effector positions in step change reference test.

In Table 4 shows ISE index comparison between three controllers for step change reference test wherein the performance of Fuzzy-SMC Controller is the best according to ISE index.

Table 4. ISE step change reference test.

\begin{tabular}{|c|c|c|c|c|c|}
\hline & PI & SMC & Fuzzy-SMC & $\boldsymbol{\Delta}_{\mathbf{1}} \%$ & $\boldsymbol{\Delta}_{\mathbf{2}} \%$ \\
\hline$X$ & 0.0080 & 0.0039 & 0.0017 & 78.57 & 129.89 \\
\hline$Y$ & 0.0080 & 0.0039 & 0.0017 & 78.57 & 129.89 \\
\hline
\end{tabular}

\subsection{Tracking trajectory test: square}

In this test, the selected trajectory is a square whose side length is $0,4[\mathrm{~m}]$. In Figure 8 illustrates the efficiency of three designed controllers for this desired trajectory.

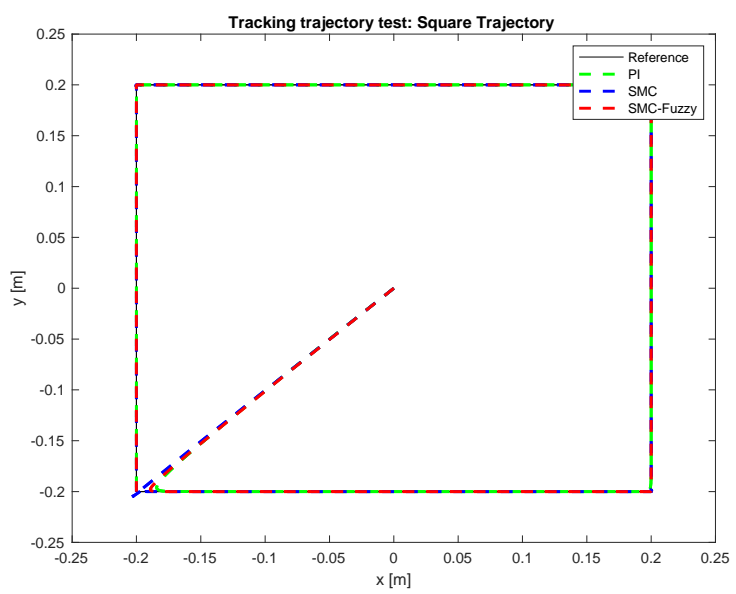

Figure 8. $X Y$ graph, square trajectory.

In Figure 9 presents an image zoom at beginning and at the corner of the square trajectory which shows Fuzzy-SMC Controller has lower overshoot than conventional SMC. 

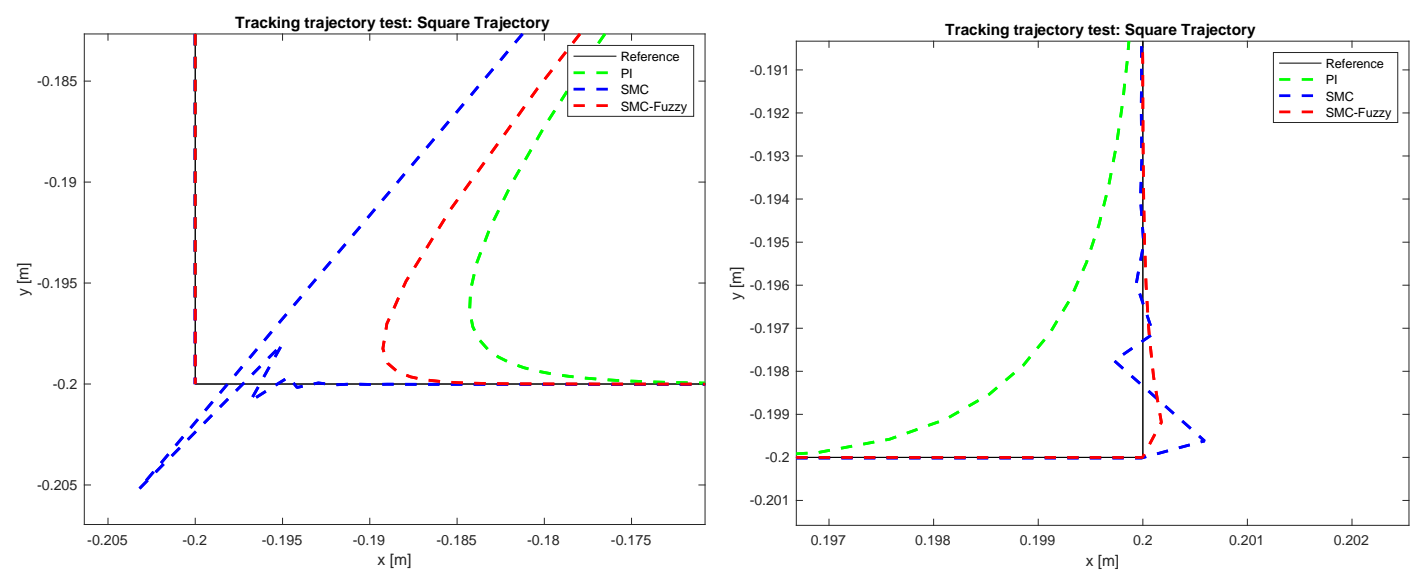

Figure 9. $\mathrm{XY}$ graph zoom, tracking trajectory test.

In Table 5 shows the ISE comparison between the three controllers for tracking trajectory test.

Table 5. ISE tracking trajectory test.

\begin{tabular}{|c|c|c|c|c|c|}
\hline & PI & SMC & Fuzzy-SMC & $\mathbf{\Delta}_{\mathbf{1}} \%$ & $\boldsymbol{\Delta}_{\mathbf{2}} \%$ \\
\hline$X$ & 0.0090 & 0.0038 & 0.0018 & 78.57 & 133.33 \\
\hline$Y$ & 0.0090 & 0.0038 & 0.0018 & 78.57 & 133.33 \\
\hline
\end{tabular}

In all tests, the proposed control law presents the lowest ISE index compared to the two controllers, the first is a PI controller and the other is a conventional SMC controller. In the two tests performed, the movement of the end effector is significantly improved because the fuzzy controller applied to the sliding surface softens the control actions which are abrupt of the SMC controller.

\section{Conclusion}

In this paper, PI, SMC and Fuzzy-SMC controllers were designed for end-effector position control of Planar 4-Cable CDDR based on the kinematic model. These controllers were able to perform trajectory tracking and step change reference wherein the results indicate which SMC with Fuzzy-PI as sliding surface with forty-nine rules presents lower setting time than PI controller and lower oscillation than the conventional SMC. The performance of the controller was evaluated in terms of integral square error (ISE) index and these results demonstrate the effectiveness of proposed controller showing an acceptable accuracy.

\section{References}

Ataei, M., \& Shafiei, S. E. (2008). Sliding mode PID-controller design for robot manipulators by using fuzzy tuning approach. En Proceedings of the 27th Chinese control conference (pp. 16-18). Citeseer.

Babaghasabha, R., Khosravi, M. A., \& Taghirad, H. D. (2014). Adaptive Control of KNTU Planar Cable-Driven Parallel Robot with Uncertainties in Dynamic and Kinematic Parameters. Recuperado 26 de octubre de 2018, de /paper/Adaptive-Control-ofKNTU-Planar-Cable-Driven-Robot-BabaghasabhaKhosravi/3cf12282c9a37211f8f7adbc5e667a1436317626

Camacho, O., \& Smith, C. A. (2000). Sliding mode control: an approach to regulate nonlinear chemical processes. ISA Transactions, 39(2), 205-218. https://doi.org/10.1016/S0019-0578(99)00043-9 
Gallina, P., Rossi, A., \& Williams II, R. L. (2001). Planar cable-direct-driven robots, part ii: Dynamics and control. En ASME. DECT2001 ASME Design Engineering Technical Conference. Pittsburgh: ASME Publisher (Vol. 2, pp. 1241-1247).

Ghosh, A., Sen, S., \& Dey, C. (2015). Design and real-time implementation of a fuzzy PI controller on a servo speed control application. En Signal Processing and Integrated Networks (SPIN), 2015 2nd International Conference on (pp. 384-387). IEEE.

Herrera. (2017). A Blended Sliding Mode Control with Linear Quadratic Integral Control based on Reduced Order Model for a VTOL System. Recuperado de http://repositorio.educacionsuperior.gob.ec/handle/28000/4641

Jin, X., Jun, D. I., Pott, A., Park, S., Park, J.-O., \& Ko, S. Y. (2013). Four-cable-driven parallel robot. 제어로봇시스템학회 국제학술대회 논문집, 879-883.

Khosravi, M. A., \& Taghirad, H. D. (2014). Robust PID control of fully-constrained cable driven parallel robots. Mechatronics, 24(2), 87-97.

Nabi, A. (2013). Design of fuzzy logic PD controller for a position control system. International Journal of Engineering and Management Research, 3(2).

Oh, S.-R., \& Agrawal, S. K. (2003). Cable-suspended planar parallel robots with redundant cables: Controllers with positive cable tensions. En IEEE International Conference on Robotics and Automation (Vol. 3, pp. 3023-3028). IEEE; 1999.

Palm, R. (1992). Sliding mode fuzzy control. En Fuzzy Systems, 1992., IEEE International Conference on (pp. 519-526). IEEE.

Villacres, J., Herrera, M., Sotomayor, N., \& Camacho, O. (2017). A fuzzy sliding mode controller from a reduced order model: A mobile robot experimental application. En Control, Decision and Information Technologies (CoDIT), 2017 4th International Conference on (pp. 0674-0678). IEEE.

Williams li, R. L., \& Gallina, P. (2003). Translational planar cable-direct-driven robots. Journal of Intelligent and Robotic systems, 37(1), 69-96.

Williams, R. L., Gallina, P., \& Rossi, A. (2001). Planar cable-direct-driven robots, part i: Kinematics and statics. En Proceedings of the 2001 ASME Design Technical Conference, 27th Design Automation Conference (pp. 178-186).

Zanotto, D. (2011). Analysis and development of cable-driven robotic devices. 